América sin nombre, n. ${ }^{\circ} 22$ (2017) 61-72

DOI 10.14198/AMESN.2017.22.05

ISSN: 1577.3442 / eISSN: 1989-9831

Fecha de recepción: 20/09/2017

Fecha de aceptación: 26/10/2017
Puede citar este artículo como:

SAndoval, Carlos. "La guerra de los días (acerca del relato breve en Venezuela)». El cuento hispanoamericano del siglo XXI. Agustín Prado Alvarado (coordinador). América sin Nombre, 22 (2017): 61-72, DOI: 10.14198/AMESN.2017.22.05

Link para este artículo: http://dx.doi.org/10.14198/AMESN.2017.221.05

\title{
La guerra de los días (acerca del relato breve en Venezuela)
}

\author{
The war of the days \\ (on Venezuelan short story)
}

\author{
Carlos Sandoval* \\ Universidad Central de Venezuela
}

\section{Resumen}

En este artículo se evalúa el estado del cuento venezolano del lapso 2001-2016 de manera sintética, estableciendo algunas marcas críticas que caracterizan esa manifestación narrativa en el período señalado. La intención es ofrecer una panorámica del género en el país con base en el difícil contexto socio-cultural que vive Venezuela desde la asunción al poder de la llamada «revolución bolivariana», sin desconocer ciertos antecedentes que permitieron el actual estado de cosas. En tanto objeto artísticamente comunicativo, el cuento resulta un precioso instrumento de indagación de esta realidad en una tierra donde abundan sus cultores.

Palabras clave: narrativa venezolana, cuento venezolano, siglo xxi, literatura venezolana.

\begin{abstract}
This paper summarily examines the status of Venezuelan short story between 2001 and 2016, establishing some critical marks typical of this narrative form in that period. It's intended to offer a panoramic view of the genre based on the difficult socio-cultural context which Venezuela is steeped in since the rise to power of the so called 'Bolivarian Revolution'. Certain precedents which contributed to the current situation aren't overlooked here. As an artistic communication object, the short story turns out to be a precious instrument of inquiry of this reality in a land plentiful of its practitioners.
\end{abstract}

Keywords: Venezuelan narrative, Venezuelan short stories, 21th century, Venezuelan literature.

\section{De aquellos polvos}

1. Tal vez la más sensible de las artes impregnada por el contexto sociopolítico, la narrativa venezolana de los últimos veinte años revela las huellas de ese influjo de manera perentoria, como ha ocurrido en otros instantes del pasado. El aserto no desconoce los rasgos estéticos que permiten la cristalización y reconocimiento de las obras (esencia y naturaleza de la práctica creativa), tan solo indica una constancia

\footnotetext{
* Licenciado en letras (ucv), magister en literatura venezolana (UCV), magister en literatura latinoamericana (Universidad Simón Bolívar). Crítico literario. Profesor de la Universidad Central de Venezuela, adscrito al Instituto de Investigaciones Literarias. Experto en Literatura Venezolana con varios libros publicados en el área.
} 
y la aspereza de un terreno fustigado, muchas veces, por discusiones ajenas a lo literario. Así pues, en las líneas que siguen se resaltan algunas materializaciones (temáticas, estilísticas, formales) del arco 20012016; un examen sintético que deja fuera el análisis de conjuntos narrativos pertenecientes a un autor específico en favor del estudio de casos puntuales o de aspectos relacionados con el campo cultural del lapso. No se trata de una pequeña historiografía ni de un inventario de títulos, sino de una valoración crítica hecha con base en las marcas más destacables del período.

2. A fines de la década del ochenta (febrero 27-marzo 03 de 1989) se produce «El Caracazo», un motín generalizado que devino ruptura del tejido civil, el cual alcanzó una trascendencia que aún no logramos asimilar en todos sus matices, no obstante la considerable bibliografía que en varias disciplinas hoy podemos reunir ${ }^{1}$. Acaso por ello todavía continúa apareciendo, con la fuerza de un trauma simbólico, en nuestras expresiones literarias, bien como simple referencia para ubicarnos en las temporalidades representadas o como núcleo argumental de las creaciones. No quepa duda, aquellos eventos modificaron el tranquilo discurrir de una literatura que, obviando los aspavientos promovidos por los últimos dos grupos poéticos de que tenemos cuenta-Tráfico y Guaire, se había mantenido dentro de los contornos de una práctica escritural que logró sobreponerse a las urgencias sociales gracias a una puesta en escena más estética, a tono con las bondades que un Estado boyante, desde el punto de vista económico, ofrecía a sus artistas.

Conviene recordar que en los años ochenta aún disfrutábamos (pese al «viernes negro» de 1983$)^{2}$ los

1. Véase Sanín (1989), Kornblith (1998), Herrera (2011), Rondón (2013), entre otros.

2. «Desde 1979 había comenzado en Venezuela el declive inexorable del modelo de desarrollo sustentado en la renta petrolera, expresado, en primer lugar, en el estancamiento del ritmo de la actividad económica. En 1983, la combinación de este estancamiento con los retardos del gobierno de [Luis] Herrera Campíns para refinanciar la deuda externa, junto con la situación en evolución del sistema capitalista mundial, que pasaba por ajustes profundos, desembocaron en la decisión gubernamental de devaluar el bolívar e ir a un sistema de cambio preferencial. El 21 de febrero se oficializaron estas medidas. Ese fecha se conoce en Venezuela como el Viernes Negro y fue la primera señal de alerta para la sociedad sobre la crisis económica que se prolongaría con altibajos hasta entrado el siglo XXI» (López Maya 23). beneficios de la altísima renta petrolera del decenio anterior, lo cual hizo posible sostener varias empresas culturales que, en el caso del libro, se galvanizaron en editoriales, premios, bolsas de trabajo y apoyo a la investigación. Los ochenta, entonces, significaron el aparente despabilamiento de los escritores respecto del mítico horizonte de los sesenta, la llamada "década violenta», que hizo creer a muchos (a casi todos) que el ejercicio de la literatura no era más que un apéndice de la lucha política -armada o de ideas- para imponer un sistema de gobierno distinto a la democracia representativa instaurada en $1959^{3}$.

Ese horizonte se convirtió en una barrera que rebajó las producciones de los setenta a meros divertimentos en los que el lenguaje y las estructuras fagocitaban los temas y la claridad expositiva. Quizá generalizo; no obstante, es lógico que una vez modificadas las circunstancias económicas a partir de 1974 como consecuencia del boom en los precios del petróleo de aquel momento, resultaba inoportuno exigir un cambio en la organización del Estado si éste repartía, mal que bien, dispendiosas prebendas a quienes antes lo adversaban ${ }^{4}$. Así, en los ochenta los escritores asumen las lecciones del pasado reciente y se vuelven más precavidos en el manejo de los elementos composicionales al subsumir en la materia narrativa sus posibles aspiraciones reformistas. De ese modo los versos se tornan más inteligibles sin abandonar la hondura reflexiva, los cuentos y novelas diversifican sus proyecciones de diseño y contenido, los ensayos se ocupan casi con exclusividad de asuntos literarios. Por supuesto, la crisis monetaria de 1983 puso en evidencia el frágil artesonado de un país sin verdaderas destrezas económicas. Con todo, la narrativa, casi toda ella financiada por entidades gubernamentales, alcanzó niveles que no se observaban desde los días de País portátil_(1968), de Adriano González León. Entonces, ocurrió «El Caracazo».

3. La "década violenta» corresponde, en Venezuela, a los años sesenta del siglo xx, etapa en la que se produjo una importante insurrección guerrillera que intentó emular a la Revolución Cubana. La mayoría de los narradores de aquel momento respaldaron con sus textos (de forma sinuosa o declaradamente abierta) las pretensiones de los alzados (Miliani 13-37; Rodríguez Ortiz 41-70).

4. Señala Pedro Palma que en 1974 se produjo «el primer gran aumento de los precios del petróleo de mediados de los años setenta, lo cual no sólo incrementó la captación de divisas del país, sino que paralelamente elevó súbitamente los ingresos del sector público» (160). 
3. Si bien las manifestaciones artísticas no deben estudiarse como el resultado de una línea ascendente que, comenzando desde una germinal potencialidad, se desarrollarían hasta alcanzar grados de solidez y excelencia (como pensaban los positivistas del siglo XIX), no puede negarse que a principios de la década del noventa las dinámicas de fomento de la literatura venezolana se vieron disminuidas debido a la quiebra que significó aquel levantamiento social. Los noventas se inician en medio de un profundo deterioro de las condiciones generales de vida del país, las cuales se revelaron de inmediato en el mapa literario no solo por el trasiego de esos escenarios a los textos en forma de temas o motivos, sino por la caída del apoyo sufragado por el Estado: las más importantes editoriales, que a su vez fungían como cabales promotoras de nuestros escritores (Monte Ávila, Fundarte, La Casa de Bello) ${ }^{5}$, redujeron drásticamente su producción debido a las contracciones económicas. Es la época cuando aparecen las denominadas «editoriales alternativas» (La Liebre Libre, Troya, Pequeña Venecia, Mucuglifo, Angria, Imaginaria), algunas subsidiadas con mínimos aportes del desaparecido Consejo Nacional de la Cultura; otras, resistiendo en un precario mercado. Como se ve, se trató de un deprimido ambiente en que la cauda del «Caracazo» aún se palpaba en los cientos de establecimientos en ruinas (abastos, farmacias, zapaterías) y en la pesada atmósfera de desencanto que se apoderó sin remedio de las sensibilidades.

La manera como se asumió ese desencanto tuvo, visto los avatares a que nos hemos enfrentado desde aquellas fechas, curiosas resoluciones. Ciertos narradores se sirvieron del "Caracazo» para explicar, en clave fictiva, las razones políticas que produjeron el tumulto, como se lee en varios pasajes de Después Caracas (1995), de José Balza y hasta en títulos más recientes: La ciudad vencida (2014), de Yeniter Poleo. Sin duda, esto indica el recrudecimiento del uso de materiales literarios para menesteres de carácter sociologizante (muy atenuados, como dijimos, en los ochenta), pero sin menoscabo del sentido plástico de las piezas. Un rasgo caracterizador, sea el caso de decirlo, de buena parte de la novela en Venezuela (y

5. Monte Ávila Editores fue fundada en 1968 para estimular, entre otras razones, la publicación de libros de autores venezolanos. Fundarte es la casa editora de la Alcaldía de Caracas. La Casa de Bello (hoy Casa Nacional de Las Letras Andrés Bello) es una institución cultural adscrita al Ministerio de Educación que regenta una importante empresa editora. en América Latina) que en tiempos de conmociones suele cargar las tintas.

De la exposición de causas algunos pasaron a la nostalgia e incluso al llamado por una periclitada era de efervescencias reivindicativas: Ricardo Azuaje logra notoriedad con su primera nouvelle, Juana La Roja y Octavio El Sabrio (1991), porque allí se cuestionaba, a través de uno de los personajes, el sustento ideológico de quienes -en el mundo real- participaron en la fallida lucha guerrillera de los ańos sesenta. En esa brevísima novela se muestra una de las debilidades que hizo fracasar aquel sueño de transformación: la falta de conocimiento de la doctrina marxista y sus derivados, la ausencia de un verdadero espíritu crítico y de estudio en el grueso de las filas militantes de la izquierda venezolana que pretendía desplazar por las armas al Gobierno. Un dejo de tristeza infiltra asimismo la trama: suerte de mensaje cifrado que se lamenta por la derrota y la consecuente pacificación en 1969 de los facciosos ${ }^{6}$.

Esta postura nostálgica respecto de las idealizaciones del sesenta, tomemos otro ejemplo, se incrementa en la novela con la cual se da a conocer Israel Centeno: Calletania (1992); un alegato simbólico, podría decirse, sobre la pérdida de direccionalidad en las propuestas literarias subsiguientes al repliegue de las guerrillas y al brusco cambio del panorama económico en los setenta que inyectó dinero en todas las instancias de la vida pública hasta 1983 y que concluye, dolorosamente, con «El Caracazo». En esta obra antiguos izquierdistas comprometidos con la lucha armada se transmutan, una vez legalizados sus partidos, en una especie de agentes sui géneris del orden: evitan que en el barrio prospere el tráfico de drogas, pero ellos, nobles defensores del bien común, trapichean y consumen, juegan a la doble moral de la sobrevivencia: ahora el enemigo es quien invade el territorio de venta de estupefacientes, un inusitado giro demagógico y capitalista.

Lo interesante es que la historia de Calletania deja entrever la necesidad de recuperar el vínculo con los anhelos colectivistas de los sesenta, con el sueño de establecer una república a la manera de la Cuba revolucionaria (y en algún fugaz momento -sugiere la trama- con la dictadura de Marcos Pérez

6. «La pacificación» es el nombre con que se conoce el proceso ejecutado por el Presidente Rafael Caldera para legalizar el Partido Comunista de Venezuela, inhabilitado desde 1962 como consecuencia de su participación en la lucha guerrillera. También, a otros grupos de izquierda vinculados con las guerrillas (Velásquez 299). 
Jiménez) pero, sobre todo, hace ostensible el deseo de reconectarse con la asunción del compromiso político tal como en los días candentes del conflicto inspirado en la gesta cubana lo hicieron los autores que apostaron, sin éxito, por un cambio. Es decir, en Calletania se suspira por la vuelta de un sujeto escritor con firmes ideales (advierto: no es que los de hoy no los tengan) que lo impulse a tomar acciones físicas, no solo imaginarias, en detrimento de su carrera o incluso de su vida. Lo cual resulta cuando menos contradictorio si observamos que el mismo Centeno es el autor de El complot (2002), novela donde se alegoriza el trunco asesinato de un radical presidente de izquierda muy amigo de Fidel Castro y líder de una supuesta revolución.

Estas oscilaciones argumentales e ideológicas (metaforizar un asunto político de modo positivo y luego satanizarlo) serán comunes en muchas obras de la década inaugural del siglo xxi. Tanto más después de la irrupción de Hugo Chávez en nuestro accidentado devenir, como veremos más adelante.

En general, los noventa constituyeron un árido espacio de producción narrativa en virtud de las restricciones editoras de las casas del Estado, de la débil situación socioeconómica y del letargo colectivo efecto del «Caracazo» ${ }^{7}$.

En este dificultoso panorama el rol de varias entidades privadas sería crucial para dar continuidad a ciertas iniciativas literarias: las lecturas de textos (con sus respectivas ediciones) en la desaparecida Fundación Banco Unión, los libros de la Fundación Bigott, la labor editorial de la Fundación Polar, entre otras instituciones del mismo signo.

$\mathrm{Al}$ cierre de la década súmese un nuevo factor: el fenómeno natural con saldo de muertos y desaparecidos aún incalculables: la vaguada de 1999, leitmotiv de numerosas obras. Este inesperado suceso pronto derivó en interpretaciones sígnicas a veces exageradas, como las que emprenden ciertos ensayistas y críticos al considerar aquel acontecimiento una respuesta a los profundos cambios sociopolíticos generados con la llegada de Hugo Chávez a la Presidencia de la República. Y es que la llamada "Tragedia de Vargas» es otra de nuestras heridas abiertas. De ahí su recurrencia en poemas y cuentos, novelas y ensayos, y en estudios de toda índole. ¿Fueron negligentes las

7. Algunos de los narradores sobresalientes de esa década: Juan Carlos Chirinos, Miguel Gomes, Rubi Guerra, Oscar Marcano, Juan Carlos Méndez Guédez, Ana Teresa Torres; y los mencionados Centeno y Azuaje. autoridades al atender la emergencia? ¿Pudo haberse efectuado un desalojo preventivo en las zonas más vulnerables, sobre todo si recordamos que las intensas lluvias que ocasionaron el deslave se desataron días antes de la fatídica noche? No debe olvidarse que esa semana se verificó el referéndum aprobatorio de la Constitución de la República impulsado por el Gobierno ${ }^{8}$.

Sea lo que fuere, aquella calamidad incide en distintos planos (argumentales, semánticos, como simple referencia) de la arquitectura literaria de decenas de volúmenes publicados en lo que llevamos de tercer milenio. Se trata, sin duda, de una estrategia que busca aceptar unos hechos desmesurados e incomprensibles, de una fórmula que se apoya en los mecanismos de simbolización de la palabra con el fin de producir verbalizaciones que atenúen el impacto de un destino cumplido. En el futuro mediato seguiremos topándonos con estos intentos-quizá inútiles, pero imperiosos- por descubrir los entresijos de la vaguada.

De manera tal que, marcados al alba por «El Caracazo» y por la «Tragedia de Vargas» en el cierre, los noventa no resultaron muy halagüeños para el oficio de la narrativa, aunque proveerían suficientes motivos (temas, historias) al creador. Este enrarecido ambiente se complicará todavía más en 1992 con la entrada de Hugo Chávez en nuestro imaginario, un súbito ingreso público de inéditas consecuencias para el país y su quehacer estético.

4. La mañana del 4 de febrero de 1992 todos los venezolanos estábamos pegados a la pantalla del televisor para conocer a los líderes del movimiento que desde la madrugada intentaba derrocar al Presidente de la República. Apenas apareció el teniente coronel Hugo Chávez asumiendo la responsabilidad del fracasado putsch, su imagen se tornaría presencia constante en los medios de comunicación, plataforma que pronto se convirtió en la más valiosa herramienta para intentar construir el mito en torno de su personalidad.

Pese al fracaso de la insurrección de febrero, remanentes militares de la asonada emprendieron otro intento de golpe el 27 de noviembre del mismo ańo con igual resultado: el descalabro de los sediciosos por tropas leales al Gobierno. No obstante el infortunio de ambas sublevaciones, la figura del comandante

8. Un sugerente estudio sobre la «Tragedia de Vargas» y su relación con las prácticas políticas «bolivarianas» puede leerse en Vásquez Lezama (2010). 
y su entorno colonizaron la imaginación de amplios sectores de la sociedad, trocando a los perdedores en héroes de la escaramuza. La narrativa, cómo no, recogería los vaivenes, entuertos y contradicciones originados por el momentáneo vapuleo del orden constitucional; en 1997 Juan Carlos Méndez Guédez recrea el segundo de los frustrados alzamientos en Retrato de Abel con isla volcánica al fondo y de manera premonitoria constela situaciones que luego se verificarían en la realidad venezolana al despuntar el siglo XXI.

El caso de la novela de Méndez Guédez es uno entre muchos: en adelante, casi todo lo relativo a los militares del MRB-200 (la logia de los golpistas) y su ideario - difundido prolijamente en la prensa- sería pasto de ensayos, narraciones y poemas de forma sostenida hasta los días que corren (escribo en 2017). Porque una vez que Hugo Chávez accede por vía electoral a la presidencia del país en 1998, el modelo de gobierno al que nos acostumbramos desde 1959 da paso a unos procederes personalistas que creíamos vencidos, en el cual se incorporan caprichosos modos de administración de las funciones públicas y políticas que contradicen la armonía de un Estado plural y democrático.

Así pues, arribamos a lo que algunos llamamos «la era de Chávez»: el período en que todas las manifestaciones de la vida venezolana se hallan inficionadas por la figura y ejecutorias de un militar que una vez conquistado el poder develaría su talante atrabiliario y en muchas ocasiones hasta incivil. Este es el marco dentro del cual se materializa la narrativa venezolana del siglo xxI: una nación en constante pugna respecto del modelo de Estado y Gobierno entre dos banderías sociales: la que apoya al líder de la autoproclamada "revolución bolivariana» y, del otro lado, su pertinaz adversario: gran parte de las fuerzas vivas del país.

No es este el sitio para detallar las implicaciones de ese conflicto y los efectos que ello ha causado en nuestra cotidianidad las últimas dos décadas. Sin embargo, la presencia del chavismo - una forma de operar en el mundo que desborda el terreno de lo político- ha sido tan invasiva que la mayoría de los textos literarios no pueden sustraerse de esa realidad. Esto explica que, apenas se inicia la primera administración de Hugo Chávez, el ensayo sea el género más socorrido al punto de que el consorcio internacional Penguin Random House abre en Caracas una franquicia de su sello Debate para publicar títulos que trataran de dar respuesta a la demanda de preguntas que el contexto exigía. Interrogantes sobre el caudillismo, el revés de las instituciones, las fallas de la democracia se convirtieron en apremiante temario. Aunque la abundancia de los ensayos se orienta hacia lo historiográfico-político y lo sociológico, la literatura se tornó referencia decisiva por cuanto la multiforme doctrina chavista combina antojadizas exégesis del pasado histórico con recuerdos literarios entresacados de los cuadros épicos de Venezuela heroica (1881), de Eduardo Blanco; de la novela Doña Bárbara (1929), de Rómulo Gallegos; de la reformulación poético-folclórica Florentino y el diablo (1957), de Alberto Arvelo Torrealba, entre otras recreaciones.

Justo es reconocerlo: el aparatoso y espectacular transcurso de Hugo Chávez en la existencia política del país constituye una ruptura que ha incidido, por igual, en la psiquis colectiva. Cargado de atavismos, de consejas llaneras y de un pensamiento con visos autocráticos su discurso despertó viejos complejos nacionales que de inmediato reactivaron líneas literarias también dormidas: novelas y cuentos sobre héroes de la Independencia o montoneros de la Guerra Federal (1859-1863); a veces, sobre guerrilleros del siglo xx. No obstante, como rechazo a esa visión arcaizante pronto se generó una corriente de obras donde los contratiempos instrumentados por el chavismo serían recogidos en cientos de tramas narrativas.

De modo pues que impelidos por el medio los escritores asumieron retratar aún más la turbidez de un ambiente sociopolítico donde cada día se juega la estabilidad de las formas de concordia ciudadana y, quién puede saberlo, su destino como civilización.

5. Una de las características resaltantes del campo literario venezolano de los primeros tres lustros del siglo XXI se relaciona con el volumen de las ediciones de autores locales financiadas por casas transnacionales (Santillana, Ediciones B, Planeta, Norma, Random House Mondadori). Este apoyo se debió quizá a la creencia de que al formar un público cautivo mediante el ensayo era posible llevar agua al molino de otros géneros. El discurso ensayístico lograría extraordinario alcance en el mercado gracias a su maleable condición: sin el deber metodológico de producir conclusiones sobre los fenómenos socioculturales relacionados con la política del chavismo, su flexible naturaleza promovió acaso una resuelta demanda de títulos (o una desmedida sobre oferta) que al mismo tiempo originaría la impresión de un interés por la lectura en capas sociales antes refractarias al saber libresco. No hay estadísticas fiables que 
avalen los comportamientos del lector en Venezuela (Kozak Rovero, «Políticas culturales de Estado» 293308); con todo, se hace difícil pensar que uno de los reactivos benéficos del proceso "bolivariano» haya sido el ejercicio de la lectura, tanto más por cuanto muchos de los ejemplares editados por aquellas compañías fueron a parar con rapidez en las ventas de saldos?.

Lo que sí es cierto es que desde el 2003, al menos, la producción editorial privada (incluyendo la de varias casas nacionales) aumentaría sus catálogos al incorporar nuevos creadores o, simplemente, reeditando obras legitimadas por el canon. El Estado, por su parte, indujo una agresiva política editora que cristalizó, a partir de 2005, en la Biblioteca Básica de Autores Venezolanos de Monte Ávila (la cual vino a sustituir la célebre colección Eldorado) y luego, desde 2006, en el establecimiento de la Fundación Editorial El perro y la rana (además de las otras instancias gubernamentales dedicadas al rubro). Ambos sectores -el público y el particular- apostaron por una ostensible difusión de textos literarios convencidos tal vez de la existencia de esos lectores.

Sin políticas de lectura efectivas el esfuerzo estatal se iría diluyendo en la medida en que se agotaran los recursos (estábamos en otra espiral de exorbitantes ingresos petroleros), en tanto que los editores privados se dieron de bruces con la realidad: no había suficientes compradores para un retorno expedito de las inversiones.

Como quiera que sea, entre el 2003 y el 2011, grosso modo, asistimos a una suerte de florecimiento literario sustentado en el número de títulos publicados, lo cual puso a circular la idea de que quizá vivíamos un boom en el cuento y la novela. La especia alcanzaría fuerza entre algunos comentaristas y críticos, pero su fortuna acabó al no soportar el más mínimo escrutinio: las medidas con base en las cuales se levantaba resultaron espurias: los libros computados pertenecían sólo a empresas privadas, en muchas ocasiones los tirajes (por lo general, bajos) no llegaron a abandonar los almacenes, la efervescencia se restringió a piezas específicas.

Ahora bien, es indudable que esta omnímoda apuesta editorial trajo provechosos corolarios: concursos, ferias, congresos, foros, charlas. La bonanza coincidió, asimismo, con el despunte de las redes

9. Rafael Osío Cabrices sostiene la tesis, sin embargo, de que gracias a la «revolución bolivariana» hoy se lee más en el país (311-322). sociales (revistas electrónicas, blogs) y con el ingreso, digamos, de una nueva generación de narradores publicitada por el mismo ímpetu ${ }^{10}$. La movilidad del ambiente no implicaba, sin embargo, un correlato en la buena marcha del mercado ni en el calado de las obras en una amplia lectoría, salvo casos muy puntuales (la narrativa de Fedosy Santaella, las novelas de Eduardo Sánchez Rugeles, los textos híbridos de Héctor Torres). No quiero decir que las novísimas letras del país se precipitaron, apenas salidas de la imprenta, al olvido; tan solo se mantuvieron en los niveles de venta y lectura (mis cálculos son empíricos) a que nos hemos acostumbrado, pese a la batahola y al obvio aumento demográfico que puede influir en una errática percepción.

Con todo, debe reconocerse que en los primeros ańos del siglo xxi tres libros se tomaron como prueba del supuesto boom: Falke (2004), de Federico Vegas; La enfermedad (2006), de Alberto Barrera Tyszka; y El pasajero de Truman (2008), de Francisco Suniaga. Es sabido que la novela, en tanto estructura literaria donde convergen variadas aspiraciones para tratar de comprender el sinuoso comportamiento humano, es el género representativo de la cultura occidental desde, por lo menos, fines del siglo XIX. Más aún, resulta el formato que emancipa, en el contexto de la globalización, la literatura de un país. Por ello, cuando en 2006 La enfermedad, de Barrera Tyszka, obtiene el Premio Herralde de Novela fallado por la Editorial Anagrama (Barcelona, España) muchos pensaron que al fin nuestros materiales literarios (no solo la narrativa) se proyectarían internacionalmente. (Barrera ratificaría el dominio de sus recursos expresivos al hacerse merecedor de otro importante certamen: el Premio Tusquets de Novela 2015 por Patria o muerte, pero ya nadie hacía referencias al hipotético boom ni a nada parecido).

Por supuesto, la pieza de Barrera Tyszka llenó de justos réditos a su creador (ha sido traducida a varios idiomas y, por segunda vez, premiada en China); sin embargo, respecto de su potencial entendimiento como avanzadilla para dar a conocer la escritura creativa de Venezuela en el exterior la repercusión fue relativa. Por ejemplo, la Editorial Candaya de Barcelona (Espańa) se dio a la tarea, a partir de 2004,

10. Una prueba lo constituyen las varias antologías y muestras publicadas en el lapso: Gómez Jiménez (2006), Torres y Torres (De la urbe al orbe 2006), Guerra (2007), Torres y Torres (Quince que cuentan 2008), Torres y Torres (Tiempos de ciudad 2010), Sandoval (2013), Marcotrigiano (2016), entre otras. 
de publicar algunos autores venezolanos consagrados por la tradición: María Auxiliadora Álvarez, José Barroeta, Victoria de Stefano, Ednodio Quintero. Lo mismo vale para la valenciana Pre-Textos con la salvedad de que esta casa editora ha publicado, hasta el momento cuando escribo, tres autores recientes: Adalber Salas Hernández (Premio Arcipreste de Hita 2014), Fedosy Santaella (Premio Internacional Ciudad de Barbastro 2016 y finalista del Herralde de Novela en 2013) y Camilo Pino. (Los otros escritores integrados al catálogo de Pre-Textos pertenecen a generaciones anteriores y a varios géneros: Igor Barreto, Rafael Cadenas, Vicente Gerbasi, Gustavo Guerrero, Antonio López Ortega, Yolanda Pantin, Luis Pérez Oramas). ¿Hay un interés por lo venezolano? Sí, pero muy comedido y, sobremanera, por autores reputados.

En relación con Falke y El pasajero de Truman la resonancia de estas obras se debió a factores distintos a los vinculados con el éxito de Barrera Tyszka y La enfermedad (un trabajo novelesco con ostensible densidad lírica). Federico Vegas, hasta ese momento poco conocido en el ambiente literario -pese a sus libros sobre arquitectura, a tres volúmenes de cuentos y a una nouvelle-, de pronto ve ampliado su radio de influencia cuando recrea en Falke (2004) un traumático episodio de nuestra historia: la fallida expedición de un grupo de militares y civiles contra la tiranía de Juan Vicente Gómez en 1929. Esta anécdota calzó muy bien en una sociedad polarizada (la posterior al golpe de Estado sufrido en 2002 por el gobierno de Hugo Chávez y su rutilante vuelta) ${ }^{11}$ pues acaso servía para ilustrar, metafóricamente, los acontecimientos vividos en el país (manifestaciones callejeras, paro petrolero, oposición de gremios empresariales) entre el 2001 y el 2003, y para evidenciar cómo ciertos sectores políticos pretendieron sustituir, de forma muy torpe e ilícita, al régimen chavista. En adelante, la carrera de Vegas como narrador no ha hecho más que consolidarse.

Por su parte, la entrada de Francisco Suniaga en el escenario de nuestra literatura se produjo de forma categórica: en 2005 publica La otra isla, una novela bien articulada-profunda- que atrapó con celeridad la atención del público y la crítica. Ese prometedor inicio agenciaría la edición de El pasajero de Truman (2008), texto que, igual que Falke de Vegas, fue recibido por un saturado contexto sociopolítico que tal

11. En abril de 2002 Chávez fue defenestrado del poder durante 48 horas. Véase López Maya et. al. (2012); Nelson (2012). vez entendió la historia narrada -un funcionario de relaciones exteriores camino a la Presidencia de la República- en una perspectiva alegórica: la demencia del protagonista constituye quizá una representación de la enfermedad del poder. Más todavía al considerar que el autor modeló ese personaje con base en una importante figura histórica venezolana.

Suniaga ha publicado otros trabajos, pero aún no supera, todo hay que decirlo, la efectividad de sus dos primeros títulos.

Completemos el cuadro con un texto adicional: Blue Label/Etiqueta azul (2010), de Eduardo Sánchez Rugeles, ganadora de la única edición del Premio Arturo Uslar Pietri. En esta novela el autor fija un momento distintivo de nuestra existencia sociocultural mediante una sencilla trama: la búsqueda de un abuelo francés perdido en Los Andes venezolanos a quien la protagonista (estudiante de secundaria de un costoso colegio) desea exigirle el reconocimiento de su parentela gala y de esa manera abandonar -con nuevo gentilicio- el país. Marcharse era el deseo de miles de coterráneos (aún lo es) al momento de publicarse la obra, de allí su arraigo entre los jóvenes de clase media. Este motivo parece haber accionado un dispositivo pulsional que hizo de la pieza un fetiche y, por supuesto, un éxito de ventas. Sánchez Rugeles ha continuado explorando en sus textos narrativos la condición juvenil con sostenida aquiescencia.

\section{Estos lodos}

6. De modo pues que este es el contexto en el cual se despliega buena parte del cuento venezolano de los lustros iniciales del siglo xxi. Sobra ańadir que el peso del referente extraliterario (lo social, la política, lo antropológico) no disminuye los valores artísticos que componen las obras. Antes bien, se engrana a la maquinaria estética y de esa manera se nos ofrece una interpretación plástica de la realidad. En este sentido, puede señalarse que la violencia -en cualquiera de sus manifestaciones- resulta uno de los temas recurrente en muchos de los relatos del lapso que cubre este artículo. Así, por ejemplo, queda retratado en «Melodía desencadenada» (un hombre mata a otros por causas fútiles 125-137), de Héctor Torres, y en varios de los textos que integran Gasolina (2012), de Eduardo Febres. Destaca, por la manera brutal en que se desarrollan las acciones (violación y muerte de una chica), el trabajo «300 gramos de sexo de baja pureza» (95-109), de Omar Mesones, y el volumen Payback (2009), de Lucas García París, donde el 
tratamiento de la maldad no tiene, en muchos casos, la más mínima traza etiológica ${ }^{12}$.

No obstante, y como acontece en todo sistema literario, otros temas obseden las necesidades creativas de los cuentistas venezolanos del período: las pulsiones sexuales, los desengaños amorosos (con sus cuotas de soledad y a veces de melodrama), los conflictos familiares, el exilio voluntario. Así, el sexo como motivación básica que acciona el comportamiento de los personajes se condensa en el libro de Leo Felipe Campos Sexo en mi pueblo (2009), pero también destaca en los conjuntos narrativos $Y$ nos pegamos la fiesta (2014), de Víctor Alarcón; Héroes (2012), de Mardon Arismendi; El último día de mi reinado (2014), de Manuel Gerardo Sánchez, respectivamente. Y en docenas de relatos de otros cuentistas; verbigracia: "Jorge y el dragón» (35-57), de Enza García Arreaza; «La carpa» (105120), de Federico Vegas; «La última foto» (11-15) (aquí con tintes incestuosos y perversos), de Carlos Villarino ${ }^{13}$.

En relación con las derrotas ocasionados por el amor varios de los textos de Gabriel Payares recogidos en sus tres libros: Cuando bajaron las aguas (2008), Hotel (2012) y Lo irreparable (2016) constituyen sólidas incursiones en el tema. Lo mismo hallamos en los volúmenes El amor en tres platos (2007) y El regalo de Pandora (2011), ambos de Héctor Torres; y en Las guerras intimas (2011), de Roberto Martínez Bachrich; Piernas de tenista rusa (2012), de Jesús Ernesto Parra; y Ana no duerme (2007), de Keila Vall De la Ville, entre otros autores y títulos.

Por su parte, Miguel Hidalgo Prince en el libro Todas las batallas perdidas (2012) y Leopoldo Tablante en Mujeres de armas temer (2005) escriben con perspicacia acerca de los conflictos generados en familias que no aceptan oficios $u$ orientaciones sexuales en algunos de sus miembros (una tendencia expresiva recorrida, asimismo, por otros narradores).

12. Otros autores que desarrollan historias en torno de la violencia social o política: Rodrigo Blanco Calderón (Los invencibles 2007); Héctor Concari (Fuller y otros sobrevivientes 2005, Yo fui chofer de Dilliger 2008); Sonia Chocrón (La virgen del baño turco y otros cuentos falaces 2008); Gisela Kozak Rovero (En rojo 2011); Carolina Lozada (La culpa es del porno 2013).

13. Es claro que se trata de un tema universal, de allí que la lista podría ampliarse. Por lo demás, es obvio que los cuentistas (y sus textos) a los que me refiero no se adscriben a una exclusiva línea narrativa o temática.
Las últimas dos décadas Venezuela ha conocido el fenómeno de la emigración. Hasta la llegada de Hugo Chávez al poder, los venezolanos no solíamos establecernos en otros territorios; la crisis sociopolítica y sus derivados económicos ha hecho que millones de connacionales ${ }^{14}$ abandonen el país en procura de mejores condiciones de vida. Esta situación ha impactado, desde al menos 2002, la faena narrativa al extremo de que, como en el caso del mal llamado boom, algunos comentaristas perciben la existencia de una «literatura venezolana del exilio»; un asunto sin duda problemático debido a las implicaciones que el término "exilio" comporta en América Latina cuando se asocia a diversas trayectorias escriturales (citemos tres casos notorios: Guillermo Cabrera Infante, Ángel Rama, Roberto Bolaño). Fuera lo que fuere, hay dibujos del tema en textos de varios autores: Rodrigo Blanco Calderón («Flamingo» 123-142), Liliana Lara («Los jardines de Salomón» 99-131), Jesús Miguel Soto («La república de Fennelly» 105-116); y en otros autores anteriores, como Juan Carlos Chirinos, Miguel Gomes, Juan Carlos Méndez Guédez, Slavko Zupcic ${ }^{15}$.

Otro aspecto temático - producto quizá del contexto- se relaciona con una especie de desasimiento en el comportamiento de los personajes, un dejarse vivir por las circunstancias, digamos, pero sin ningún tipo de nihilismo. Es lo desencadena las acciones en varios de los cuentos de Carlos Ávila recogidos en Desde el caleidoscopio de Dios (2006) y en Mujeres recién bañadas (2008); también en los trabajos de Hensli Rahn integrados en Dinero fácil (2014) y en los de Ricardo Waale que forman parte de Memorias en la laguna (2003).

14. Véase https://www.revistavenezolana.com/2016/07/mas2-millones-venezolanos-pais/ También http://www.elnacional.com/noticias/sociedad/exodo-venezolanolidera-cifras-migratorias_75441

15. Una aproximación anecdótica al problema puede verse en Cordoliani (2013). Algunos volúmenes de cuentos de Chirinos publicados en el lapso: Homero haciendo zapping (2003), La manzana de Nietzsche (2015); de Gomes: Viviana y otras historias del cuerpo (2006), El hijo y la zorra (2010), Julieta en su castillo (2012); de Méndez Guédez: Hasta luego, Mister Salinger (2007), La bicicleta de Bruno y otros cuentos (2009), Ideogramas (2012), La noche y yo (2016); de Zupcic: Médicos taxistas, escritores (2011). Las carreras narrativas de estos autores comenzaron a principios de la última década del siglo xx o antes. 
Si bien los temas de la narrativa breve en Venezuela publicada entre 2001 y 2016 dan para emprender un trabajo de análisis mayor ${ }^{16}$, ahora quiero detenerme en otras particularidades que, por igual, destacan en aquellas materializaciones: el empleo de otras especificidades discursivas sin riesgo de la estructura genológica y los equipajes simbólicos de los que se apropian los narradores en el aparejo de sus historias.

Aun cuando podría resultar una herramienta peligrosa en un formato breve como el cuento, el uso del tono ensayístico sostiene muchas de las anécdotas en las composiciones de José Tomás Angola conjuntadas en Todas las ciudades son Isabel (2010) y en La mirada del suicida al caer y otros relatos (2016). Otro tanto ocurre en varias piezas del libro Pequeños episodios (2007), de David Colina Gómez, y en los cuentos del tomo El infierno era como Platón decía (2015), de Marino Nava Contreras.

En el campo de los enseres arquitectónicos-llamémoslos de ese modo- sobresalen los montajes parecidos a los seriales de televisión estadounidenses en los relatos de Fedosy Santaella (Piedras lunares 2008, Terceras personas 2015); Roberto Echeto (Breviario galante 2004, La máquina clásica 2011); Salvador Fleján (Intriga en el Car Wash 2006, Miniaturas salvajes 2012); Mario Morenza (Pasillos de mi memoria ajena 2007, La senda de los diálogos perdidos 2008).

Asimismo, es obvia la adscripción al cómic en los textos de Lucas García París ya referidos, pero también en los de Echeto y en algunos de Santaella.

Las imitaciones de formas prefijadas: cuaderno de apuntes, correo electrónico, carta, crónica, informe devienen recursos frecuentes.

Hay, asimismo, atisbos de pequeños Bildungsromans, si se me permite el salto de género, en piezas de Angola, Campos, Concari, Rahn, Vegas.

Los juegos metaficcionales se perciben en casi todos los cuentistas del período, entre los que destacan los relatos de Krina Ber contenidos en Para no perder el hilo (2009) y los de Rodrigo Blanco Calderón que forman parte de Las rayas (2011).

16. Por ejemplo, podríamos referirnos al uso de marcadas referencias literarias como tema de muchísimos relatos de Rodrigo Blanco Calderón, de Judit Gerendas y de Carmen Vincenti; o la representación de cierta religiosidad mágica como sustrato importante en el imaginario de los personajes construidos por Enza García Arreaza, Luis Laya o Sol Linares. Otro motivo: el alcance de un sólido nivel de conciencia gracias a experiencias trascendentales sufridas por los protagonistas en ciertas ficciones de José Tomás Angola, de Krina Ber, de Héctor Concari o de Dayana Fraile.
Respecto de las subcategorías del género, se constata el empleo de dispositivos del relato negro o del policial en los trabajos de Echeto, Fleján, Morenza, Santaella. Por su parte, el cuento fantástico es catalizado por unos pocos (Martínez Bachrich, Colina Gómez, Santaella); entretanto, el rubro de la ciencia ficción tiene en John Manuel Silva un solvente practicante (Afrodita C. A. y otras empresas fracasadas 2014).

Finalizo con un balance sobre el equipaje de bienes simbólicos que contienen muchos cuentos del arco temporal 2001-2016. En ellos es notable la necesidad de representar actividades y guiños ideológicos de la clase media venezolana, acaso como un intento de sobrevivencia ante el moroso desmantelamiento social al que se ha visto sometida en estos años, pero sin duda como crítica feroz a sus frívolas actitudes. En contraparte, numerosos relatos perfilan, a veces con marcado expresionismo, algunos de los asideros espirituales y los sueños de las clases económicas menos solventes (Granizo 2011, de Dayana Fraile; 24 2010, de Luis Laya; Cuentafarsas 2010, de Sol Linares).

De manera global, abundan las referencias musicales. Trátese de interpretaciones académicas o populares, en innumerables cuentos del lapso las historias giran en torno de los versos de una melodía o de extrañas ligaduras sonoras. En otros casos, el arte musical sirve de cortina o fondo para las acciones ejecutadas por los personajes.

Junto con la música aparecen otras marcas recurrentes de la cultura pop: superhéroes de dibujos animados y de series, cantantes, actores cinematográficos. Es común toparse con muchas anécdotas cuyo soporte argumental es una película o una evocación televisiva.

No obstante el auge de utensilios pop trufados en las piezas, la llamada cultura institucionalizada tiñe de sabiduría unas cuantas historias. Las referencias a obras pictóricas, literarias, filosóficas, operísticas y de la denominada música clásica son, por igual, frecuentes.

Concluyo con una curiosidad: en decenas de textos la representación de las drogas ha sido despojada de todo estigma moral; cumple, si se quiere, una función recreativa.

Este apretado panorama del cuento venezolano apenas roza el universo de un sistema narrativo que, por fuerza de las circunstancias, sobrevive en medio de un inaudito caos social. Una situación lamentable que no parece tener una mediata salida favorable para el bien común. Contra todo, la literatura trata 
de mantener vivos ciertos valores mientras retrata, sin quebranto para el arte, la tragedia de un país en bancarrota.

\section{Bibliografía}

Alarcón, Víctor. Y nos pegamos la fiesta. Caracas: Editorial Equinoccio, 2014.

Angola, José Tomás. La mirada del suicida al caer y otros relatos. Caracas: Los Libros de El Nacional, 2016.

Angola, José Tomás. Todas las ciudades son Isabel. Caracas: Editorial Equinoccio, 2010.

Arismendi, Mardon. Héroes. Caracas: Fundarte, 2012.

Arvelo Torrealba, Alberto. Florentino y el diablo. Caracas: Editorial Rex, 1957.

Ávila, Carlos. Desde el caleidoscopio de Dios. Caracas: Editorial Equinoccio, 2006.

Ávila, Carlos. Mujeres recién bañadas, Caracas: Random House Mondadori, 2008.

Azuaje, Ricardo. Juana La Roja y Octavio El Sabrio. Caracas: Fundarte, 1991.

Balza, José. Después Caracas. Caracas: Monte Ávila Editores Latinoamericana, 1995.

Barrera Tyszka, Alberto. La enfermedad. Barcelona, España: Editorial Anagrama, 2006.

Ber, Krina. Para no perder el hilo. Caracas: Random House Mondadori, 2009.

Blanco Calderón, Rodrigo. "Flamingo». Las rayas. Caracas: Ediciones Puntocero, 2011: 123-142.

Blanco Calderón, Rodrigo. Las rayas. Caracas: Ediciones Puntocero, 2011.

Blanco Calderón, Rodrigo. Los invencibles. Caracas: Random House Mondadori, 2007.

Blanco, Eduardo. Venezuela heroica. Caracas: Imprenta Sanz, 1881.

Campos, Leo Felipe. Sexo en mi pueblo. Caracas: Ediciones Puntocero, 2009.

Centeno, Israel. Calletania. Caracas: Monte Ávila Editores Latinoamericana, 1992.

Centeno, Israel. El complot. Caracas: Alfadil Ediciones, 2002.

Chirinos, Juan Carlos. Homero haciendo zapping. Cumaná: Dirección de Cultura y Extensión, Universidad de Oriente / Fundación José Antonio Ramos Sucre, 2003.

Chirinos, Juan Carlos. La manzana de Nietzsche. Madrid: Ediciones La Palma, 2015.

CHOcrón, Sonia. La virgen del baño turco y otros cuentos falaces. Caracas: Ediciones B, 2008.

Colina Gómez, David. Pequeños episodios. Caracas: Fundación Editorial El perro y la rana, 2007.
Concari, Héctor. Fuller y otros sobrevivientes. Caracas: Random House Mondadori, 2005.

Concari, Héctor. Yo fui chofer de Dilliger. Caracas: Random House Mondadori, 2008.

Cordoliani, Silda (comp.). Pasaje de ida. 15 escritores venezolanos en el exterior. Caracas: Editorial Alfa, 2013.

Echeto, Roberto. Breviario galante. Caracas: Fundación para la Cultura Urbana, 2004.

Echeto, Roberto. La máquina clásica. Caracas: Editorial Alfaguara, 2011.

Febres, Eduardo. Gasolina. Caracas: Monte Ávila Editores Latinoamericana, 2012.

Fleján, Salvador. Intriga en el Car Wash. Caracas: Random House Mondadori, 2006.

Fleján, Salvador. Miniaturas salvajes. Caracas: Ediciones Puntocero, 2012.

Fraile, Dayana. Granizo. Caracas: Fundación Editorial El perro y la rana / Red de Bibliotecas e Información de estado Monagas / Fondo Editorial Biblioteca de Temas y Autores Monaguenses, 2011.

Gallegos, Rómulo. Doña Bárbara. Barcelona, España: Editorial Araluce, 1929.

García Arreaza, Enza. «Jorge y el dragón». Plegarias para un zorro. Caracas: bid \& co. editor, 2012: 35-57.

García París, Lucas. Payback. Caracas: Ediciones Puntocero, 2009.

Gerendas, Judit. Volando libremente. Caracas: Editorial Memorias de Altagracia, 2000.

Gomes, Miguel. El hijo y la zorra. Caracas: Random House Mondadori, 2010.

Gomes, Miguel. Julieta en su castillo. Caracas: Artesano Editores, 2012.

Gomes, Miguel. Viviana y otras historias del cuerpo. Caracas: Random House Mondadori, 2006.

Gómez Jiménez, Jorge (comp.). Próximos. Antología de la nueva narrativa venezolana. Beijing: Embajada de la República Bolivariana de Venezuela, 2006.

González León, Adriano. País portátil. Barcelona, España: Editorial Seix-Barral, 1968.

Guerra, Rubi (comp.). 21 del XXI. Antología del cuento venezolano del siglo XXI. Caracas: Ediciones B, 2007.

Herrera, Earle. Ficción y realidad en el Caracazo. Periodismo, literatura y violencia. Caracas: Monte Ávila Editores Latinoamericana, 2011.

Hidalgo Prince, Miguel. Todas las batallas perdidas. Caracas: bid \& co. editor, 2012.

Kornblith, Marta. Venezuela en los noventa: las crisis de la democracia. Caracas: Facultad de Ciencias Jurídicas y Políticas, Centro de Estudios de Postgrado, Universidad Central de Venezuela / Ediciones IESA, 1998. 
Kozak Rovero, Gisela. «Políticas culturales de Estado en la Venezuela del siglo xxi (1999-2013). Marcelino Bisbal (ed.). La comunicación bajo asedio. Balance de 17 años. Caracas: AB UCAB Ediciones, 2016: 293-308.

Kozak Rovero, Gisela. En rojo. Caracas: Editorial Alfa, 2011.

LARA, Liliana. «Los jardines de Salomón». Los jardines de Salomón. Cumaná: Dirección de Cultura y Extensión, Universidad de Oriente, 2008: 99-131.

Laya, Luis. 24. Caracas: Monte Ávila Editores Latinoamericana, 2010.

Linares, Sol. Cuentafarsas. 2a. ed. Caracas: Fundarte, 2010.

López Maya, Margarita et. al. Golpes al vacío. Reflexiones sobre los sucesos de abril de 2002. Caracas: Lugar Común, Cooperativa Editorial, 2012.

López Maya, Margarita. Del viernes negro al referendo revocatorio. Caracas: Alfadil Ediciones, 2005.

Lozada, Carolina. La culpa es del porno. Caracas: Los Libros de El Nacional, 2013.

Marcotrigiano, Miguel (comp.). Nuestros más cercanos parientes. Breve antología del cuento venezolano de los últimos 25 años. Madrid: Kalathos Ediciones, 2016.

Martínez Bachrich, Roberto. Las guerras intimas. Caracas: Lugar Común, Cooperativa Editorial, 2011.

Méndez Guédez, Juan Carlos. Hasta luego, Mister Salinger. Madrid: Editorial Páginas de Espuma, 2007.

Méndez Guédez, Juan Carlos. Ideogramas. Madrid: Editorial Páginas de Espuma, 2012.

Méndez Guédez, Juan Carlos. La bicicleta de Bruno y otros cuentos (antología 1990-2008). Caracas: Editorial Bruguera, 2009.

Méndez Guédez, Juan Carlos. La noche y yo. Madrid: Editorial Páginas de Espuma, 2016.

Méndez Guédez, Juan Carlos. Retrato de Abel con isla volcánica al fondo. Caracas: Editorial Troya, 1997.

Mesones, Omar. «300 gramos de sexo de baja pureza». Inventario y otros relatos. Caracas: Casa Nacional de Las Letras Andrés Bello, 2007: 95-109.

Miliani, Domingo. «Diez años de narrativa venezolana (1960-1970)». Prueba de fuego. Narrativa venezolanaEnsayos. Caracas: Monte Ávila Editores, 1973: 13-37.

Morenza, Mario. La senda de los diálogos perdidos. Caracas: Editorial Equinoccio, 2008.

Morenza, Mario. Pasillos de mi memoria ajena. Caracas: Monte Ávila Editores, 2007.

Nava Contreras, Mariano. El infierno era como Platón decía. Caracas: Editorial Equinoccio, 2015.

Nelson, Brian. El silencio y el escorpión. Crónica de un golpe de estado. Caracas: Editorial Alfa, 2012.

Osío Cabrices, Rafael. «La catástrofe anotada. Apuntes para una bibliografía de la era chavista». Marcelino
Bisbal (ed.). La comunicación bajo asedio. Balance de 17 años. Caracas: AB UCAB Ediciones, 2016: 311-322.

Palma, Pedro. «La economía venezolana en el período (1974-1988): ¿últimos años de una economía rentista?». Pedro Cunill Grau et. al. Venezuela contemporánea 1974-1988. Caracas: Fundación Eugenio Mendoza, 1989: 157-248.

Parra, Jesús Ernesto. Piernas de tenista rusa, Caracas: Monte Ávila Editores Latinoamericana, 2012.

Payares, Gabriel. Cuando bajaron las aguas. Caracas: Monte Ávila Editores Latinoamericana, 2008.

Payares, Gabriel. Hotel. Caracas: Ediciones Puntocero, 2012.

Payares, Gabriel. Lo irreparable. Caracas: Ediciones Puntocero, 2016.

Poleo, Yeniter. La ciudad vencida. Caracas: Libros del Fuego, 2014.

Rahn, Hensli. Dinero fácil. Caracas: Libros del Fuego, 2014.

Rodríguez Ortiz, Oscar. «Para un esquema de los setenta». Intromisión en el paisaje. Caracas: Fundación de Promoción Cultural de Venezuela, 1985: 41-70.

Rondón, Daynir. CAP: auge y caida: segundo mandato 1989-1993. Caracas: Libros Marcados, 2013.

SÁnchez Rugeles, Eduardo. Blue Label/Etiqueta azul. Caracas: Los Libros de El Nacional, 2010.

SÁnchez, Manuel Gerardo. El último día de mi reinado. Caracas: Editorial Ígneo, 2014.

Sandoval, Carlos (comp.). De qué va el cuento. Antología del relato venezolano 2000-2012. Caracas: Editorial Alfaguara, 2013.

Sanín. Los muertos de la deuda o el final de la Venezuela saudita. 2a . ed. Caracas: Ediciones Centauro, 1989.

Santaella, Fedosy. Piedras lunares. Caracas: Ediciones B, 2008.

SANTAElla, Fedosy. Terceras personas. Caracas: Los Libros de El Nacional, 2015.

Silva, John Manuel. Afrodita C. A. y otras empresas fracasadas. Caracas: Editorial Ígneo, 2014.

Soto, Jesús Miguel. «La república de Fennelly». Perdidos en Frog. Caracas: Lugar Común, Cooperativa Editorial, 2012: 105-116.

Suniaga, Francisco. El pasajero de Truman. Caracas: Random House Mondadori, 2008.

Suniaga, Francisco. La otra isla. Caracas: Oscar Todtmann Editores, 2005.

Tablante, Leopoldo. Mujeres de armas temer. Caracas: Comala.com, 2005.

Torres, Ana Teresa y Héctor Torres (comps.). De la urbe al orbe. Nueva narrativa urbana. Caracas: Alfadil Ediciones, 2006. 
Torres, Ana Teresa y Héctor Torres (comps.). Quince que cuentan. II Semana de la Narrativa Urbana. Caracas: Fundación para la Cultura Urbana / PEN Club Venezuela, 2008.

Torres, Ana Teresa y Héctor Torres (comps.). Tiempos de ciudad. III y IV Semana de la Nueva Narrativa Urbana 2008-2009. Caracas: Fundación para la Cultura Urbana, 2010.

Torres, Héctor. «Melodía desencadenada». El regalo de Pandora. Caracas: Ficción Breve Libros, 2011: 125-137.

Torres, Héctor. El amor en tres platos. Caracas: Editorial Equinoccio, 2007.

Torres, Héctor. El regalo de Pandora. Caracas: Ficción Breve Libros, 2011.

Vall de la Ville, Keila. Ana no duerme. Caracas: Monte Ávila Editores Latinoamericana, 2007.
VÁsquez Lezama, Paula. Poder y catástrofe. Venezuela bajo la tragedia de 1999. Caracas: Editorial Taurus, 2010.

Vegas, Federico. «La carpa». La carpa y otros cuentos. Caracas: Editorial Alfaguara, 2008: 105-120.

Vegas, Federico. Falke. México: Jorale Editores, 2004.

Velásquez, Ramón J. «Aspectos de la evolución política de Venezuela en el último medio siglo». Ramón J, Velásquez et. al. Venezuela moderna. Medio siglo de historia 1926-1976. Caracas: Fundación Eugenio Mendoza, 1976: 1-385.

Villarino, Carlos. «La última foto». El otro infierno. Caracas: Ediciones B, 2009: 11-15.

Vincenti, Carmen. Cuentos de cuentos. Caracas: Editorial Equinoccio, 2008.

WAALE, Ricardo. Memorias en la laguna. Caracas: Monte Ávila Editores Latinoamericana, 2003.

Zupcic, Slavko. Médicos taxistas, escritores. Valencia, España: Ediciones Publiberia, 2011. 